
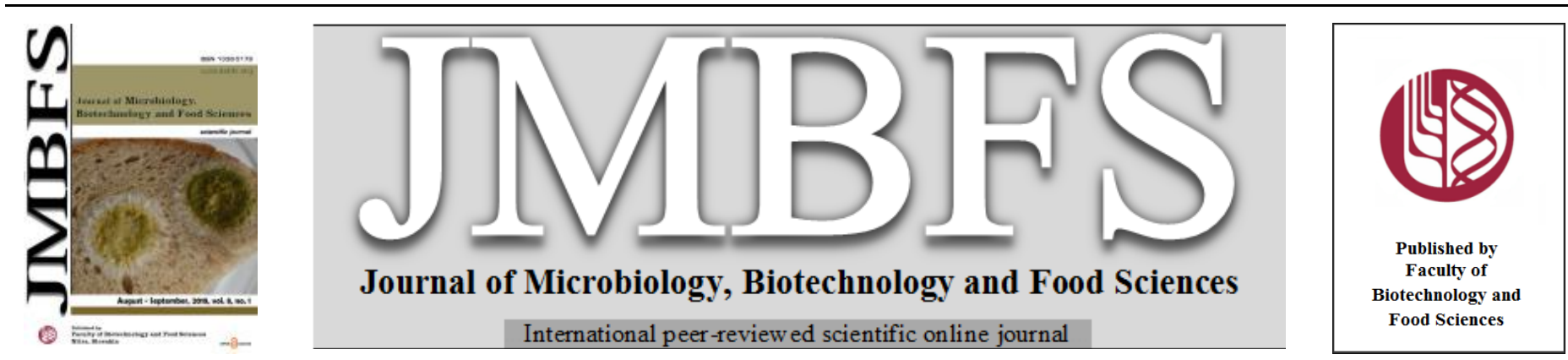

\title{
BIOGENIC SYNTHESIS AND CHARACTERIZATION OF GOLD NANOPARTICLES BY A NOVEL MARINE BACTERIA MARINOBACTER ALGICOLA: PROGRESSION FROM NANOSPHERES TO VARIOUS GEOMETRICAL SHAPES
}

\author{
Rashmi Gupta ${ }^{1}$ and Padmini Padmanabhan ${ }^{2 *}$ \\ Address(es): Dr. Padmini Padmanabhan

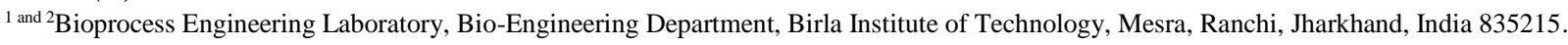

*Corresponding author: padmini@bitmesra.ac.in

doi: 10.15414/jmbfs.2018.8.1.732-737

\section{ARTICLE INFO}

Received 30. 4. 2018

Revised 10. 7. 2018

Accepted 11. 7. 2018

Published 1. 8. 2018

Regular article

open 2 access

\begin{abstract}
Metal nanoparticle biosynthesis is gaining impetus as the process is cost-effective and ecofriendly with a variety of application of them in biomedical field. In this study, biosynthesis approach for the synthesis of gold nano particles (GNPs) has been investigated using marine bacteria, Marinobacter algicola isolated from Indian sector of Southern Ocean. The biosynthesis of GNP was the obtained by adding $\mathrm{HAuCl}_{4}-1 \mathrm{mM}$, to the bacterial cell lysate supernatant (CLS) maintained at $\mathrm{pH} 7.0$, incubated at $30{ }^{\circ} \mathrm{C}$ for $24 \mathrm{~h}$. The bioreduction of auric chloride was supposedly accomplished by enzyme nitrate reductase from the bacterial cellular bio mass, and was established using the FTIR data. GNP characterization from SEM, AFM and TEM exhibited formation of various shaped GNPs like spherical, triangular, pentagonal and hexagonal, possibly from enzyme nitrate reductase which is relatively different from GNPs synthesized so far reporting only single shape from single enzyme. XRD analysis determined the FCC structure of GNPs. DLS result display the GNPs formed is of mean size of 4-168 nm with an average of $74 \mathrm{~nm}$. Being able to control the shapes of nanoparticles as a time dependent factor can be considered path breaking leading to its multipurpose biomedical application. The present research also studied the antimicrobial effect of GNPs on various pathogens.
\end{abstract}

Keywords: Marinobacter algicola, Biosynthesis, Gold nanoparticles, TEM, XRD, Nitrate reductase

\section{INTRODUCTION}

Nanotechnology has opened up novel fundamental and functional frontiers in materials science and engineering. Since past one decade the use of microorganisms for the synthesis of nano sized materials especially metallic, bimetallic and metal oxide nanoparticles has gained popularity (Ahmad et al. 2003). Synthesis of nanoparticle through biological route has emerged as a nove approach because it highlights the intersection of nanotechnology and biotechnology. It is environmentally benign technology in material synthesis. Chemical and physical methods were earlier employed to synthesise metal nanoparticles because of easy modulational and functional behavior of nanostructures and their affordability was in range (Li et $\boldsymbol{a l} ., 2011)$. Due to toxic effects of several solvents used in chemical and physical methods there has been a shift in the paradigm recently to utilize biological sources as warehouse for nanoparticle synthesis (Zhang et al., 2011).

The biomolecules can act as reducing agents and even as capping agents for nanoparticles production which makes them more promising and beneficial. For example, plant (Mapala et al. 2017, Pulit et al., 2013; Francis at al., 2014) and microorganism like bacteria (Seshadri et al., 2012; Malhotra et al., 2013), fungi (Li et al., 2012), actinomycetes (Ahmad et al., 2003) and algae (Rajathia et al., 2012; Singh et al., 2013) are exploited at wide variety to synthesise inorganic materials, especially metal nanoparticles. Prokaryotic bacteria have principally attracted the most attention in the zone of biosynthesis of metal nanoparticles which accounts for the fact that bacterial cells have the competency to fight environmental pressure and have the capability of growing in presence of high metal concentrations. Gold is among the most popular and one of the most widely studied metals when it comes to biological synthesis of nanoparticles. Beveridge and Murray (1980) printed first research study for the biosynthesis of gold nanoparticles (GNPs) by utilizing bacteria Bacillus subtilis. Since then researchers have exploited numerous microorganisms to synthesise variety of metal, non- metal, metal oxide and bi-metallic nanoparticles with their further consideration in various applications including biological and biomedical like drug delivery, therapeutic, diagnostic, nanomedicines, imaging technology and nanocomposites for artificial implants.
By far maximum reports have glorified the use of soil microflora for the production of metal nanoparticles (Bajaj et al., 2012). Marine bionanotechnology is a sensational and approaching area of research. The biologically different marine environment has a great potential and a very promising future for nanoscience and nanotechnology. Marine microorganisms hold a good potential for the biosynthesis of gold and silver nanoparticles and as a matter of fact marine water is acknowledged to be the most containing richest source of gold in nature. Sargassum wightii was the first reported marine algae to be utilized to synthesise monodispersed gold nanoparticles by Singaravelu $\boldsymbol{e t}$ al. (2007). Silver nanoparticles were synthesized by using marine fungus Penicillium fellutanum (Kathiresan et al., 2009). Recently in past few years, use of marine bacteria to synthesise gold and silver nanoparticles was successfully demonstrated by Sharma et al. (2012) and Seshadri et al. (2012). Further, silver nanoparticles biosynthesis using marine organisms was also successfully demonstrated by Malhotra et al. (2013). And now the thrust area is to explore marine organisms for biogenic metal nanoparticles production because marine flora and fauna easily acclimatize to biotic and abiotic stress and extreme environmental conditions. Also, noble metals are expensive thus minimizing the amount of material needed to produce nano sized particles and less wastage helps to control costs. Biosynthesizing nanoparticles cuts down waste disposal cost also because it is eco friendly

Synthesis of nanoparticle using environment friendly manner is one of the biggest concern for scientist, which required exploration of new resources. With the intention to advance the investigation on microbes from marine resources proficient of producing nanoparticles, 4 marine bacteria were screened for their ability to synthesise gold nanoparticles using Auric chloride $\left(\mathrm{HAucl}_{4}\right)$ as the precursor. The experimental results led to identification of a novel bacterial strain Marinobacter algicola that can synthesize gold nanoparticles. The bioreduction of the gold ions resulted in the production of exceptionally unreactive and stable gold nanoparticles in the size ranging from 4 to $168 \mathrm{~nm}$ with an average size of $74 \mathrm{~nm}$. Furthermore, The GNPs synthesized using whole bacterial cells were characterized by measuring Surface Plasmon Resonance (SPR) using UV-Vis Spectrophotometer, Scanning Electron Microscopy (SEM), Dynamic Light Scattering (DLS), Transmission Electron Microscopy (TEM), Zeta Potential Analyzer, Fourier Transform Infrared Spectroscopy (FTIR),Energy 
Dispersed Spectroscopy (EDS), powdered X-ray diffraction (XRD) and Atomic Force Microscope Imaging (AFM). Till now, the researches on use of marine bacteria for nano particles synthesis are scarce. Here we report the synthesis of metallic gold nano particles by strain of Marinobacter algicola isolated from marine waters of Southern Ocean of Indian Sector. Controlling the shape of nanocrystals is critical to application in catalysis, photonics and biomedical applications. An endeavor has been made to study the evolution of specific structures of gold nanoparticles over the course of reaction as a time dependent factor.

\section{MATERIALS AND METHODS}

\section{Micro-organism and chemical used}

The marine bacterium was isolated from water samples collected from Southern Ocean particularly in Indian sector and found to be a novel strain of Marinobacter algicola, which happen to be a gram negative rod shaped bacterium (Gupta et al., 2015). Chloroauric acid $\left(\mathrm{HAuCl}_{4}\right)$ by Sigma Aldrich was used as precursor for synthesis of gold nanoparticles.

\section{Production of biomass}

The bacterium Marinobacter algicola was grown on zobella marine broth grown $\left(30{ }^{\circ} \mathrm{C}\right.$ temperature and a shaker rpm of 150 ) for 24 hours. The biomass was harvested by centrifugation $\left(10,000 \mathrm{rpm}, 4{ }^{\circ} \mathrm{C}\right.$ for $\left.15 \mathrm{~min}\right)$. Both supernatant (ST) and cell biomass were taken in order to determine whether the enzyme responsible for GNPs synthesis is intracellular or extracellular. The cell biomass was twice washed in phosphate buffer $(\mathrm{pH} 7,0.05 \mathrm{M})$ by centrifuging at $6,000 \mathrm{rpm}$ and then dissolved in $50 \mathrm{ml}$ distilled water and was ultrasonicated ( $5 \mathrm{mins}, 30$ second pulse) to break the cell wall and bring out the enzyme in aqueous system. The solution was centrifuged $\left(10,000 \mathrm{rpm}, 4{ }^{\circ} \mathrm{C}\right.$ for $\left.15 \mathrm{~min}\right)$ and cell lysate supernatant (CLS) was taken, discarding the pellet. Figure 1 shows the complete schematic representation of the step by step procedure of GNP biosynthesis using M. algicola

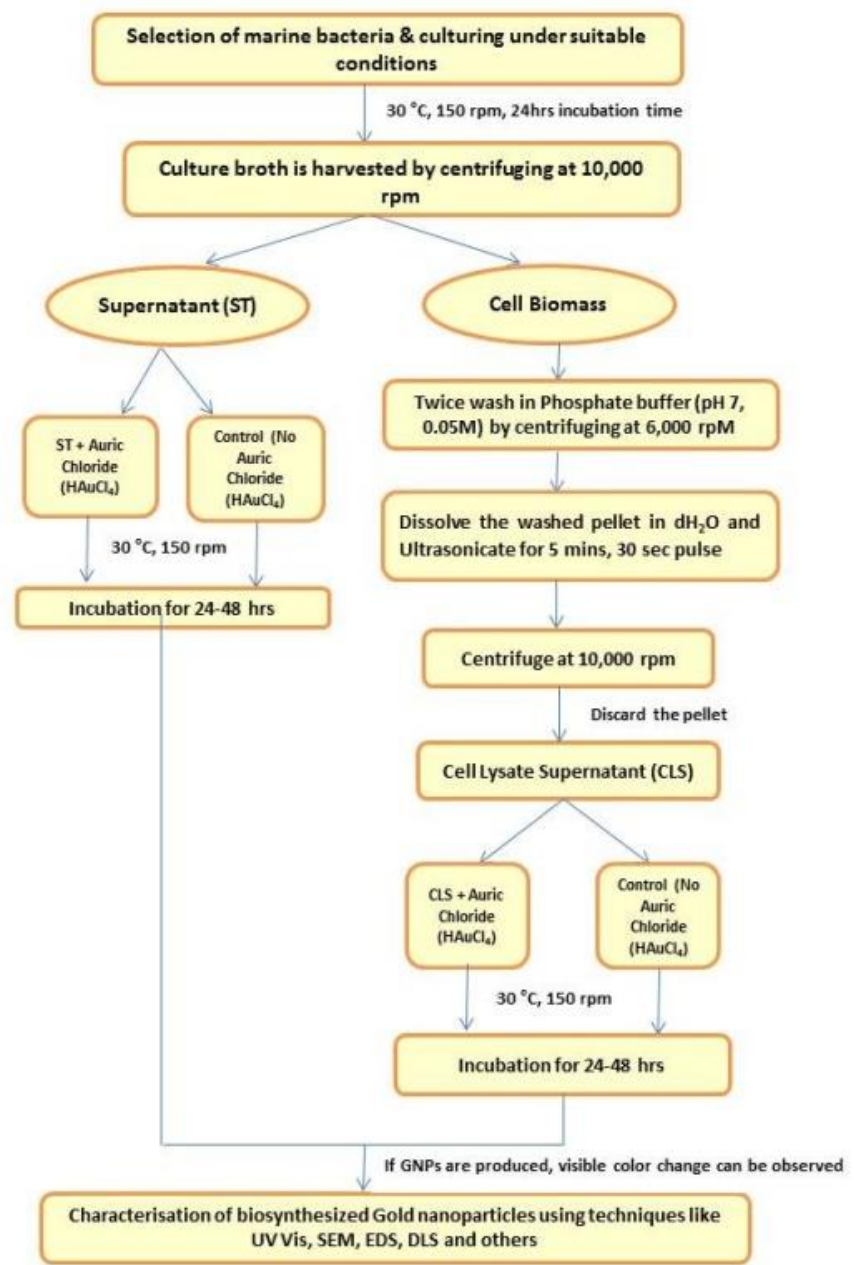

Figure 1 Flowchart representing the steps involved in biosynthesis of GNPs using Marinobacter algicola

\section{Biosynthesis of GNPs}

For synthesis of gold nanoparticles, $\mathrm{HAuCl}_{4}-1 \mathrm{mM}$ was mixed with $25 \mathrm{ml}$ of supernatant (S) and CLS in a $100 \mathrm{ml}$ Erlenmeyer flask each and agitated at $30^{\circ} \mathrm{C}$ at rpm of 150 for 72 hours. Control (without the $\mathrm{HAuCl}_{4}$, only supernatant) was also run along with the experimental flask (Malarkodi et al., 2013). After 6 hours a clear visible color change was observed in CLS that was derived out of cell biomass after ultrasonication. This proved that the involved enzyme is intracellular in nature. The reaction was continued up to 72 hours to study the shape and size of GNPs formed. Samples were withdrawn at regular time intervals and were subjected to distill water washing before using them for characterization.

\section{Characterization of GNPs}

Synthesized GNPs were confirmed by subjecting the sample to UV-Vis spectroscopy surface plasmon measurements in between range of $200-700 \mathrm{~nm}$. Further the reaction mixture was centrifuged at 6,000 rpm 10 minutes and pellet was resuspended in distilled water filtered through Millipore filter $(0.45 \mu \mathrm{m})$. An aliquot from this filtrate containing gold nanoparticles was used for DLS and Zeta Potential, SEM, TEM, AFM, FTIR, XRD and EDS studies. DLS and Zeta potential analysis was done to confirm the particle size and charge of the synthesized GNPs. SEM and TEM analysis was done to predict shape and morphology of the GNPs. The surface morphology was studied by analyzing the GNP coated mica films through AFM. Moreover presence of specific metals in the aliquot was investigated by energy dispersive spectroscopy (EDS). The synthesized GNPs were also analyzed using Spectrofluorophotometer to measure the excitation frequency of GNPs. Lastly the sample was lyophilized to remove water and convert GNPS into dry powdered form to get XRD measurement done and was mixed with $\mathrm{KBr}$ pellet for FTIR analysis.

\section{Antimicrobial activity}

Antimicrobial property of GNPs was studied by disc diffusion method. The biosynthesized GNPs were examined against 4 pathogenic bacterial cultures namely Bacillus subtilis, Staphylococcus aureus, Salmonella typhi and Pseudomonas fluorescens. The bacterial cultures were homogenously spread on a nutrient agar plate. Discs were soaked in different concentrations $(5,10$ and 15 $\mu \mathrm{g} / \mathrm{ml}$ ) of biogenic GNPs and were placed on the plates along with one control. The plates were incubated at $37{ }^{\circ} \mathrm{C}$ for $24 \mathrm{~h}$ for appearance of zone of inhibition around the disc.

\section{Instrumentation}

The Uv-vis spectra was recorded at room temperature using Perkin Elmer, USA Lambda-25 spectrophotometer with samples in quartz cuvette. The particle size and zeta potential was measured using Malvern Inst., UK; Nano ZS zetasizer. It can measure particle size in between $0.6 \mathrm{~nm}$ to $6 \mu \mathrm{m}$. Photoluminescence spectra was recorded on Shimadzu, Japan; RF-5301PC spectrofluorophotometer Scanning electron microscopy (SEM) studies were performed using a Jeol, Japan; JSM 6390LV electron microscope operated at high vacuum mode with a resolution of $3 \mathrm{~nm}$ at a voltage of $30 \mathrm{KV}$. For the SEM measurements, a drop of a solution containing the gold nanoparticles was casted on a carbon tape coated SEM holder. After letting the film to stand for 2 minutes, the grid was dried in hot air oven at a temperature of $60-80{ }^{\circ} \mathrm{C}$ and then sample was platinum coated for 60 seconds using Jeol JFC-1600 Auto Fine Coater before the measurement. Energy dispersive spectroscopy (EDS) was done using Oxford Instruments DCL7673. Fourier transform infrared (FTIR) spectra was also recorded at room temperature on a Shimadzu Corpn., Japan; IR-Prestige 21 FTIR spectrometer. A small amount of water free dried gold nanoparticles was mixed with Potassium Bromide $(\mathrm{KBr})$ and was grounded into fine powder to be loaded onto the holder for FTIR measurement. The wavenumber range of the FTIR spectrometer was $7500-350 \mathrm{~cm}^{-1}$. The Atomic Force Microscopy was done using NT-MDT, Russia Solver Pro-47 in semi contact mode. The sample was prepared by coating small thin small mica films with drop of gold nanoparticle solutions and allowing them to dry at room temperature for 4 hours. To determine FCC structure of GNPs, powdered XRD was done on a Rigaku, Japan, SmartLab 9kW operating system with $\mathrm{Cu}-\mathrm{KA} 1$ radiation and wavelength $1.5406 \AA$.

\section{RESULTS AND DISCUSSION}

Addition of $1 \mathrm{mM}$ aqueous $\mathrm{HAuCl}_{4}$ solutions to bacterial cell lysate supernatant (CLS) led to the appearance of dark purple color in solutions after $24 \mathrm{~h}$ of reaction, indicating the formation of gold nanoparticles (Nangia et al., 2009). Because of excitation of surface plasmon vibrations in the gold nanoparticles, these colors arise. Figure $2 \mathrm{~A}$ shows the clear visual observation that color of reaction solution turned from fade yellow to pinkish purple which act as preliminary step to predict successful synthesis of GNPs. The UV-Vis spectra (figure $2 \mathrm{~B}$ ) recorded shows the gold surface plasmon resonance (SPR) band occurred at $560 \mathrm{~nm}$ and confirms the presence of GNPs. The sample was kept for 
three and nine months to check the stability of produced GNPs. As shown in figure 2B (curve 2) it clearly signifies that the GNPs in the solution were quite stable with only little aggregation as SPR band occurred at $550 \mathrm{~nm}$ (Haiss $\boldsymbol{e t}$ al. 2007). Although the sample when analyzed after 9 months (after ultrasonication) showed SPR band at 530nm which concludes that the particles have faintly agglomerated thus leading to slightly bigger size nanocluster formation and hence a blue shift in the peak.

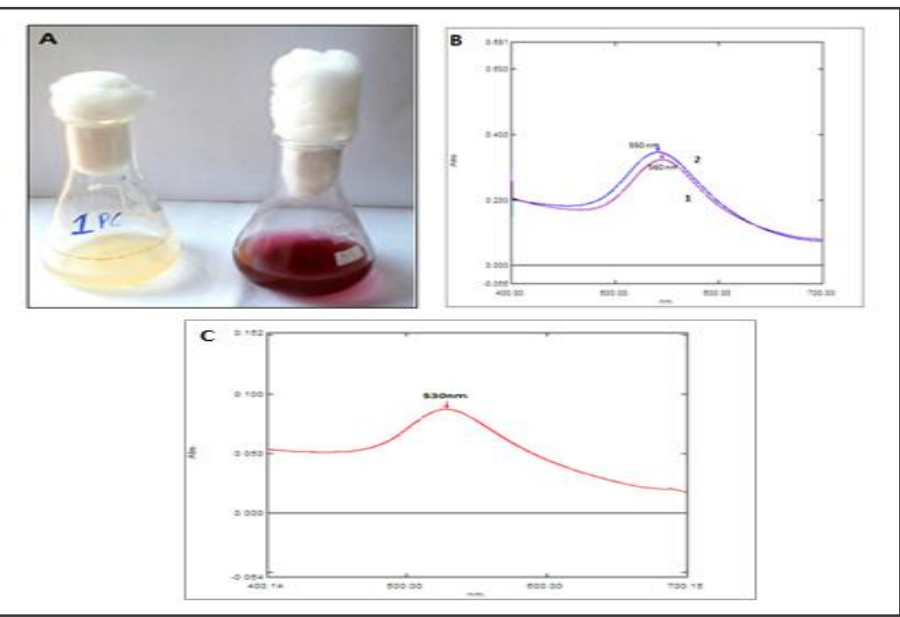

Figure 2 (A) Image of flask showing visible color change thus proving biosynthesis of GNPs by marine bacteria Marinobacter algicola (B) UV-Vis absorption spectra of synthesized GNPs by marine bacteria M. algicola for $24 \mathrm{~h}$ (curve1) and kept for three months after reaction (curve2) (C) UV-Vis absorption spectra of synthesized GNPs after 9 months

Dynamic Light scattering was used to determine particle size distribution profile of biosynthesized GNPs by Marinobacter algicola. The size histogram shows the GNPs are in range of $4-168 \mathrm{~nm}$ with average particle size $74 \mathrm{~nm}$. Figure 3 represents the respective size histogram and intensity graph. The time dependent fluctuation of scattering of light by nanoparticles undergoing Brownian movement acts as a principle to measure the particle size distribution of gold nanoparticles (Suresh et al., 2011). In order to check stability of formed GNPs, the samples were tested after 9 months as well. Since the particles underwent aggregation, thus the average particle size increased from $74 \mathrm{~nm}$ to $79 \mathrm{~nm}$ which can be observed in Figure 3(A) and (C) but the overall size distribution histogram remains almost similar.
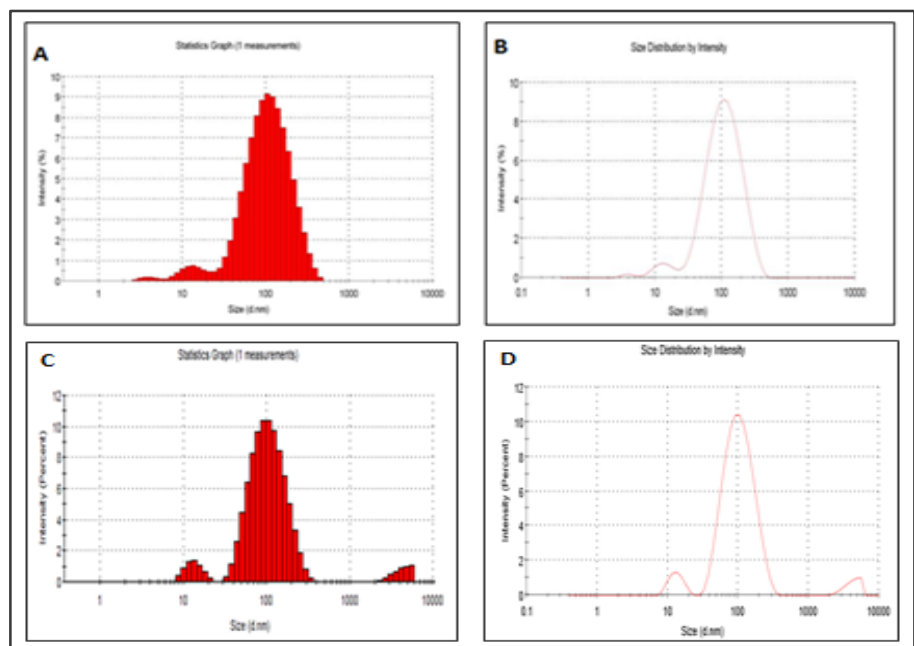

Figure 3 (A) Particle size distribution histogram (B) Size distribution intensity graph of GNPs synthesized by Marinobacter algicola obtained by particle size analyzer (C) Particle size distribution histogram after 9 months (D) Size distribution intensity graph of GNPs synthesized by after 9 months

The net electrostatic potential or surface charge of any particle in suspension is given by Zeta potential, thus this feature plays major role in determining the stability of biosynthesized GNPs. Nanoparticles with Zeta Potential values more than $+25 \mathrm{mV}$ or less than $-25 \mathrm{mV}$ characteristically have better degrees of stability. Zeta potential is used to predict the monodispersity or agglomeration of particles. High zeta potential (either positive or negative) $(>25 \mathrm{mV}$ ) lead to monodispersity. Low zeta potential $(<5 \mathrm{mV})$ leads to agglomeration. Figure 4 shows the zeta potential of solution mixture of GNPs when evaluated was found to be $-31.0 \mathrm{mV}$ which confirms that the nanoparticles are fairly monodispersed in the solution. The conductivity comes out to be $0.9 \mathrm{mS} / \mathrm{cm}$ which is very low justifying their relative stability as conductivity is inversely proportional to stability and hence they can be widely used in biomedical application. (Dubey $\boldsymbol{e t}$ al., 2010).

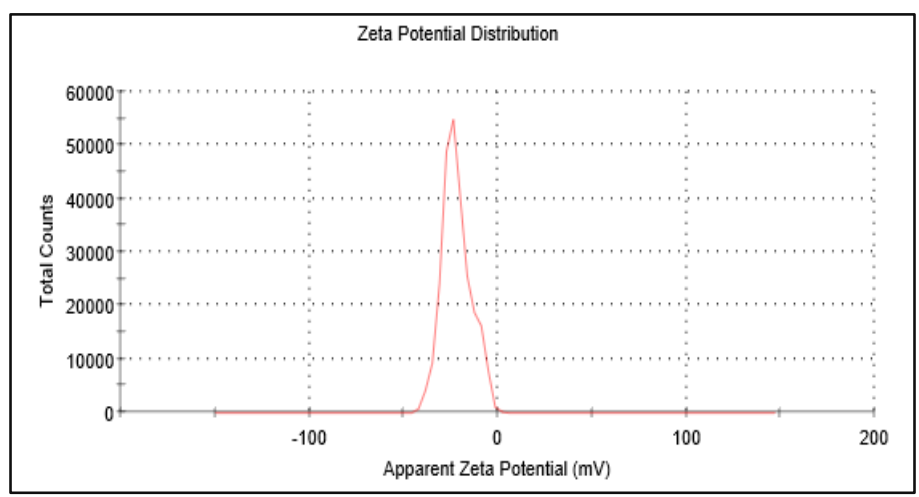

Figure 4 Zeta potential Distribution graph of biosynthesized GNPs by Marinobacter algicola

The surface morphology and characteristics were studied by subjecting thin film of GNP sample to atomic force microscopy (AFM). The 3D view and topological map of the surface of GNP film is clearly visible by AFM analysis in figure 5 . The uneven surface depicts the formation of gold nanoparticles. The result shows both the individual and aggregated GNPs. The hump depicts big sized particles or the agglomerated GNPs which fuse to take various exotic shapes in the later phase of reaction while the small individual peaks shown in the image are of single spherical GNPs. Scanning electron microscopy (SEM) measurements support the AFM result about the structural features and surface morphology of GNPs formed. Well-dispersed spherical and cubical shaped glittering gold nanoparticles can be seen from SEM images shown in figure 5 . GNPs with intermittent aggregation can be seen. Both smooth and rough surfaced small sized GNPs can be observed.

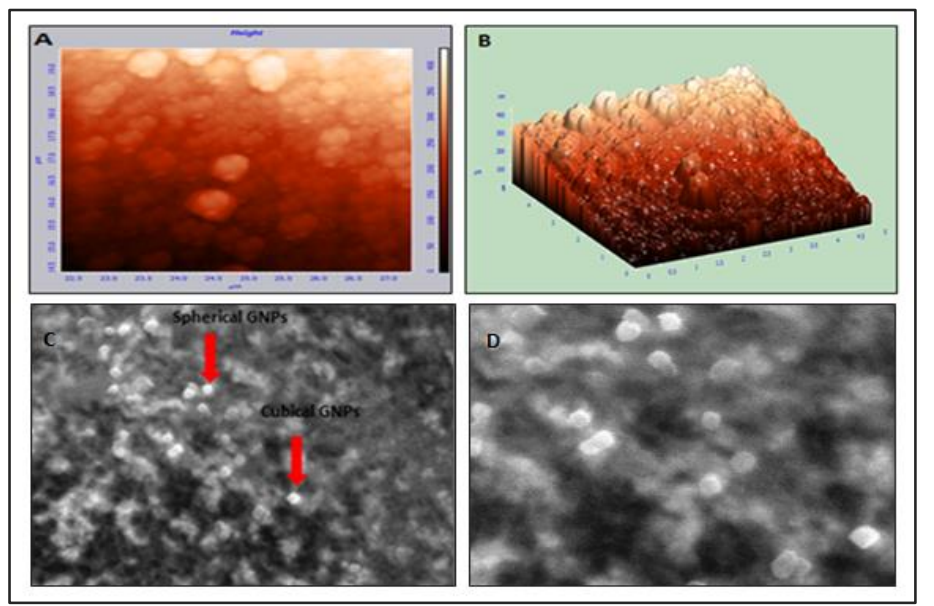

Figure 5 Atomic Force Microscopy (AFM) image of biosynthesized GNPs (A) Topographic View (B) 3-Dimensional View and SEM image of GNP by Marinobacter algicola (C) showing presence of glittering gold nanoparticles of spherical and cubical shape(D) magnified image of the gold nanoparticles

The TEM images present a clearer image of GNPs formed during the course of reaction. TEM image of the GNPs synthesized were in agreement with the UVVis spectroscopy. The TEM image of the gold nanoparticles synthesized majorly consist of spherical shaped nanoparticles ranging from 4-168 nm. Some uniquely shaped nanoparticle like $3 \mathrm{D}$ nanotriangles, penta and hexagonal can also be seen in the image. To study it in detail, an experiment set was employed at an interval of 2 hours each from $0 \mathrm{~h}$ to $12 \mathrm{~h}$ and thereafter 24, 36, 48, 60 and $72 \mathrm{~h}$ of time interval. Initially the GNPs synthesized were nanospheres in the size range of 4 to $28 \mathrm{~nm}$ which clearly indicates commencement of nucleation phenomenon. Further after $12 \mathrm{~h}$, larger size GNPs were observed of nanospheres, nano triangular and nano prism shape reaching up to $80 \mathrm{~nm}$ indicating growth of crystals. The nanospheres probably merge and fuse with each other to take shape of triangle. At 60 and $72 \mathrm{~h}$ GNPs formed were a pool of mix population comprising of spherical and 3 dimensional triangular, pentagonal, hexagonal shaped nanoparticles which is due to growth of crystals occurring due to fusion of nanospheres. The TEM images clearly justifies that with increase in reaction time, the size of crystal growth increases and due to agglomeration and merging of small nanoparticles, the crystal keeps on growing and emerging into various shapes as per the various charged molecules present around leading to change of energies and imparting the stability to a particular GNP structural morphology 
(Kumari et al., 2016) These results decipher that if reaction is stopped at early stage i.e. after few hours of nucleation, spherical shaped nanoparticles are easy to obtain. If the reaction is continued beyond $12 \mathrm{~h}$ extending up to $24 \mathrm{~h}$, development of morphology from nano-sphere to nano-triangles starts to occur as a factor of time. Formation of 3D penta and hexagons were obtained after the reaction mixture is left up to $72 \mathrm{~h}$. Capping agent plays a vital role in such enzymatic reactions, since presence of them restricts the growth of nanoparticle crystal but in absence of them the crystal continues to grow and evolve into various shapes. The major amount of enzyme's active sites are blocked by substrate molecule by that time which leads to perceptive growth for the assembly of 3D penta and hexagonal nanoparticle (Mukherjee et al., 2012).
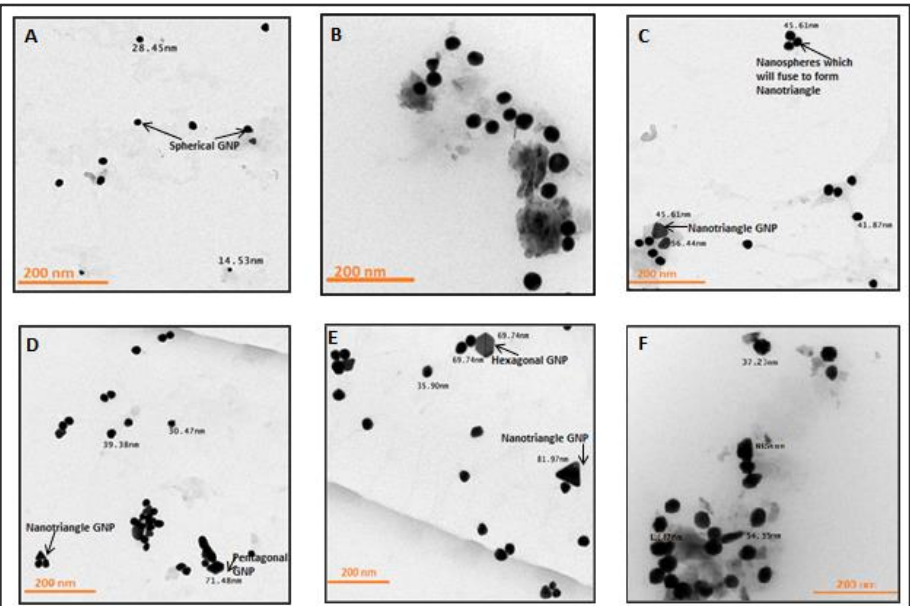

Figure 6 TEM micrographs on evolution of morphology (A) small sized spherical GNPs at 6h (B) crystal growth leading to large sized spherical GNPs (C) Emergence of triangular shaped GNPs after 12h (D) (E) \& (F) asymmetrical shaped GNPs like pentagonal and hexagonal is observed within 24 to $72 \mathrm{~h}$ along with spherical GNPs

Structural characterization studies are carried out using X-ray diffraction confirming the crystalline nature of the gold nanoparticle formed by the bioreduction of $\mathrm{AuCl}_{4}-$ ions using M. algicola. The characteristic intense peaks corresponding to (111), (200), (220) and (311) of Au are located at $2 \theta=38.08^{\circ}$, $44.39^{\circ}, 64.67^{\circ}$ and $77.52^{\circ}$ are observed (figure 7) and compared with JCPDS card number 0013110, which on the basis of similarity confirm the FCC structure of gold nanoparticle. No counterfeit diffractions owing to crystallographic impurities are observed.

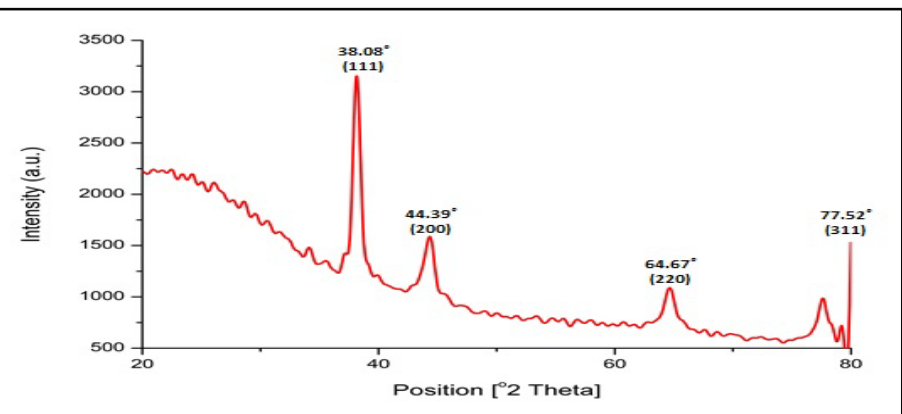

Figure 7 XRD spectrum of gold nanoparticles synthesized by Marinobacter algicola

Owing to interband transitions, metals like gold when converted to nanoparticles are found to exhibit photoluminescence. Photoluminescence occurs because excited electrons from occupied "d" bands jump into states overhead the Fermi level. Figure 8 shows that the PL spectra of gold nanoparticles are found to be luminescent with an emission at $585 \mathrm{~nm}$ for an excitation at $325 \mathrm{~nm}$. The UVvisible peak and PL emission peak appeared almost at the same wavelength range which may be due to their ability to withstand resonating surface plasmons with nominal damping. Therefore the GNP produced exhibit high efficient solitary photon-induced luminescent peak at $585 \mathrm{~nm}$. Previously biotin functionalized gold nanoparticles with a comparable PL spectra band around 522nm was also reported (Khalil et al., 2012). The luminescent and fluorescent properties of the gold nanoparticles project its possible use in therapeutic applications and as fluorescent markers for biological sensing studies and cell labeling (CastroLongoria et al., 2011).

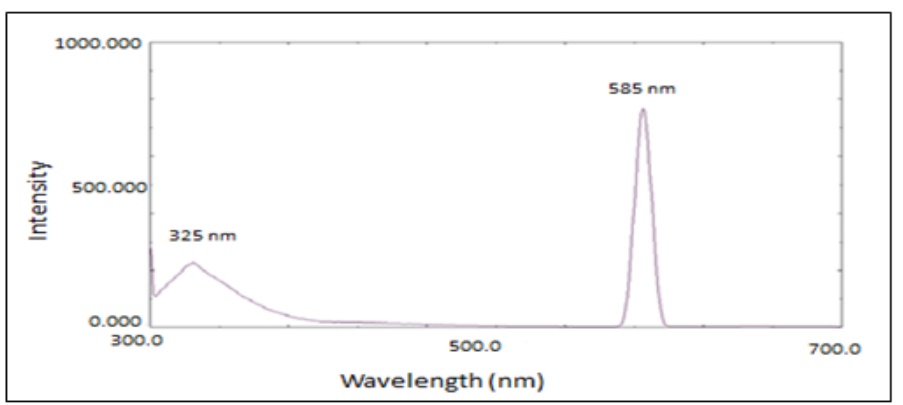

Figure 8 Photoluminescence spectra of synthesized gold nanoparticles using Marinobacter algicola

The EDS spectrum shows strong signal of gold thus confirming the production of gold nanoparticles. Figure 9 shows an EDS profile derived from reaction solution when subjected to analysis generating a sharp peak corresponding to gold (Agnihotri et al., 2009). Other elemental signals recorded like Potassium (K) and Chlorine $(\mathrm{Cl})$ are perhaps due to elements from chemicals used to adjust $\mathrm{pH}$ of broth or buffer used for washing. The EDS spectrum results of biosynthesized gold nanoparticles indicate the reduction of $\mathrm{Au}^{+2}$ to $\mathrm{Au}^{0}$ by marine bacteria Marinobacter algicola.

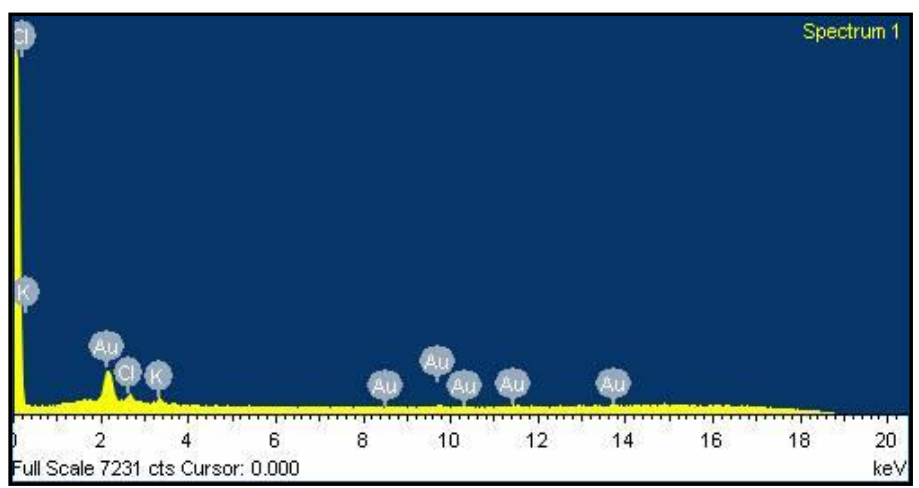

Figure 9 EDS analysis of gold nanoparticles showing characteristic peaks of gold

FTIR analysis of unwashed GNPs was done to characterize the synthesized gold nanoparticles. Figure 10 represents the FTIR spectrum which shows an intense broad absorbance at $3332 \mathrm{~cm}^{-1}$ and peak at $2924 \mathrm{~cm}^{-1}$ which is the typical characteristic of the hydroxyl functional group that are strong in nature found in alcohols, phenols and carboxylic compounds. The band at $1654 \mathrm{~cm}^{-1}$ corresponds to the amide I band of the proteins produced by the marine bacteria Marinobacter algicola. The band at $1091 \mathrm{~cm}^{-1}$ matches to the $\mathrm{C}-\mathrm{N}$ stretching vibration of aliphatic amines which is a medium strength bond. The strong band at 1543 $\mathrm{cm}^{-1}$ refers to $\mathrm{N}-\mathrm{O}$ asymmetric stretch which signifies a nitro compound. The results undoubtedly show the role of several biological moieties, containing proteins and organic compounds which must be strongly involved in GNP biosynthesis. It also predicts possible involvement of an enzyme or protein that's nitrogenous in nature. The weaker bands at $1249 \mathrm{~cm}^{-1}$ corresponds to amide III group of protein which suggests the presence of a capping agent which is responsible for stabilization of biosynthesized gold nanoparticles (Song et al., 2009).

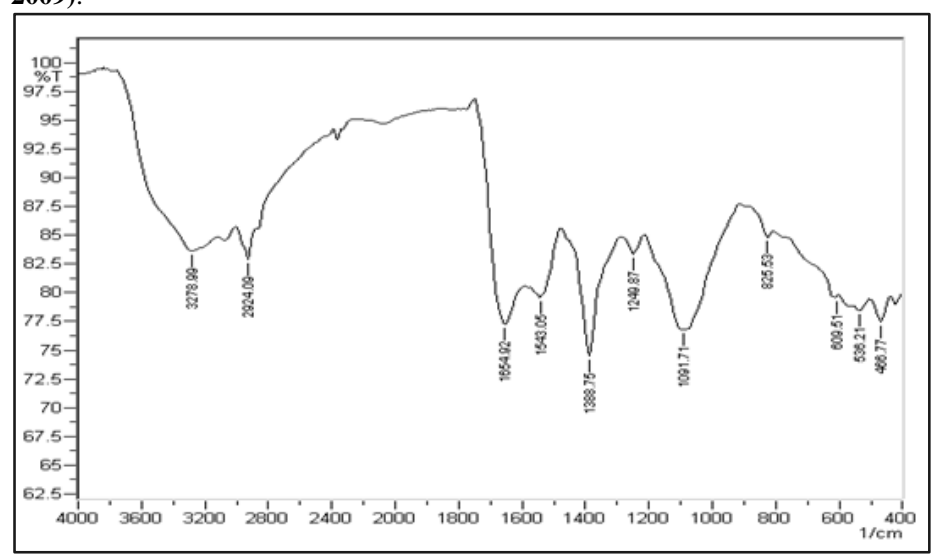

Figure 10 FT-IR spectra of biologically synthesized GNPs using Marinobacter algicola

It is already illustrated that proteins can bind to gold nanoparticles through available free amine groups or cysteine residues present in the proteins and, thus 
leading to stabilization of the gold nanoparticles by surface-bound proteins. Meanwhile, through FTIR analysis it can be easily justified that some biomolecules/proteins is possibly involved in GNP biosynthesis. The particular mechanism for GNP synthesis by reduction of the gold ions is yet to be confirmed and explained for $M$. algicola. Although NADH-dependent reductase is assumed to be involved in biosynthesis of GNPs. Earlier studies have pointed to NADH- and NADH-dependent enzymes as possible enzymes responsible in the biosynthesis of metal nanoparticles. Bioreduction of $\mathrm{Au}(3+)$ to $\mathrm{Au}(0)$ by bacteria $R$. capsulata is evidently proved previously and the same bacteria is known to secrete cofactor NADH- and NADH dependent enzymes (Feng $\boldsymbol{e t}$ al., 2007). Therefore NADH-dependent reductase may be considered responsible for GNP biosynthesis. NADH-dependent reductase is supposed to acts as electron carrier and helps in transferring electron NADH to gold ions which in turn get reduced to $\mathrm{Au}(0)$. Gupta $\boldsymbol{e}$ al have also tried to study the contribution of nitrate reductase enzyme in GNP biosynthesis using Insilco characterization approach (Gupta et al., 2014). They concluded that nitrate reductase enzyme is made up of four subunits namely alpha, beta, gamma and delta. Targeting gamma subunit and enhancing the expression of it may lead to production of more gold nanoparticles.

As studied earlier by Thirumurugan et al in 2012, antimicrobial activity of GNPs is evaluated. In this investigation, the GNPs exhibited antimicrobial activity against a variety of different pathogenic microorganisms i.e. Bacillus subtilis, Staphylococcus aureus, Salmonella typhi and Pseudomonas fluorescens. As evident from figure 11, the highest antimicrobial activity was observed against $B$. subtilis and $S$. aureus as the diameter of zone of inhibition of these two was larger as compared to rest two pathogens. The antimicrobial activity of gold nanoparticles is considered due to the penetration of GNPs into the bacterial cells leading to disruption of cell membrane and thus release of cellular contents.
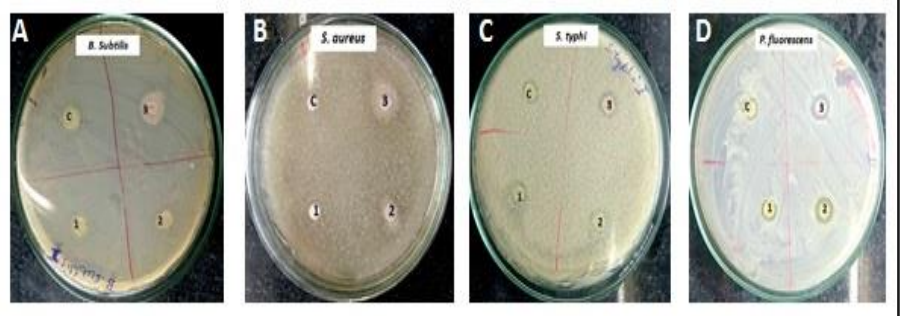

Figure 11 Antimicrobial activity of GNPs against pathogens (A) B. subtilis (B) $S$ aureus (C) S. typhi (D) P. fluorescens. Disc contains (C) sterile deionized water as control, (1) (2) and (3) are gold nanoparticles at 3 different concentration 5 $\mu \mathrm{g} / \mathrm{mL}, 10 \mu \mathrm{g} / \mathrm{mL}$ and $15 \mu \mathrm{g} / \mathrm{mL}$ respectively.

\section{CONCLUSION}

As marine microorganism live in the sea bottom, and they have been reducing a massive quantity of inorganic elements deep down the sea hence it proves that they have great potential capacity to synthesise nanoparticle. This led to exploitation of marine microorganisms to biosynthesize metal nanoparticles as a hot spot working areas in past few years. The synthesized GNPs were characterized by using UV-Visible spectroscopy, XRD, SEM, EDS, FTIR, DLS, AFM and TEM analysis. This research works successfully proves the biosynthesis of gold nanoparticle of average size $74 \mathrm{~nm}$ by a marine bacterium Marinobacter algicola. The present investigation also successfully indicates intracellular synthesis of exceedingly stable gold nanoparticles by biotransformation and these particles remain stable up to 3 months. GNPs formed are of various shapes like spherical, cubical, triangular and penta-hexagonal and hence may find wide biomedical and drug delivery applications. This study indicates involvement of enzyme nitrate reductase for GNPs synthesis and reporting multiple shapes from single enzyme. This eco-friendly procedure for the biosynthesis of GNPs is very cost effective, doesn't generates toxic byproducts and can be up scaled easily for large commercial production. Hence, our study highlights the synthesis of multiple shaped GNPs from nitrate reductase using novel microbial source which can lead to wider prospective of nanoparticle biosynthesis. Also, the synthesized GNPs were used for studying antimicrobial activity against clinically isolated organism.

Acknowledgements: The authors are thankful to Dr. Rajib Bandopadhyay, Associate Professor, The University of Burdwan, West Bengal (formerly Assistant Professor, BIT Mesra Ranchi) for sharing the marine bacterial strain collected from his South Sea expedition and giving his consent to work on them We sincerely thank TEQIP Central Instrument Facility (CIF) lab for the instrumental facilities and sample analysis. We also, thank Department of BioEngineering, BIT, Mesra, Ranchi for providing support to use the facilities and do the research studies. We would also like to thank research scholar Mr. Gourav Kumar (Department of Bio-Engineering, BIT, Mesra) for his constant support, dynamic ideas and valuable suggestions throughout the work.

\section{REFERENCES}

Agnihotri, M., Joshi, S., Kumar, A. R., Zinjarde, S., \& Kulkarni, S. (2009) Biosynthesis of gold nanoparticles by the tropical marine yeast Yarrowia lipolytica NCIM 3589. Materials Letters, 63(15), 1231-1234. DOI: https://doi.org/10.1016/j.matlet.2009.02.042

Ahmad, A., Mukherjee, P., Senapati, S., Mandal, D., Khan, M. I., Kumar, R., \& Sastry, M. (2003). Extracellular biosynthesis of silver nanoparticles using the fungus Fusarium oxysporum. Colloids and surfaces B: Biointerfaces, 28(4), 313 318. https://doi.org/10.1016/S0927-7765(02)00174-1

Ahmad, A., Senapati, S., Khan, M. I., Kumar, R., \& Sastry, M. (2003) Extracellular biosynthesis of monodisperse gold nanoparticles by a novel extremophilic actinomycete, Thermomonospora sp. Langmuir, 19(8), 3550-3553. https://doi.org/10.1021/la0267721

Bajaj, M., Schmidt, S., \& Winter, J. (2012). Formation of Se (0) nanoparticles by Duganella sp. and Agrobacterium sp. isolated from Se-laden soil of North-East Punjab, India. Microbial cell factories, 11(1), 64. https://doi.org/10.1186/14752859-11-64

Beveridge, T. J., \& Murray, R. G. (1980). Sites of metal deposition in the cell wall of Bacillus subtilis. Journal of bacteriology, 141(2), 876-887.

Castro-Longoria, E., Vilchis-Nestor, A. R., \& Avalos-Borja, M. (2011). Biosynthesis of silver, gold and bimetallic nanoparticles using the filamentous fungus Neurospora crassa. Colloids and Surfaces B: Biointerfaces, 83(1), 42-48. https://doi.org/10.1016/j.colsurfb.2010.10.035

Dubey, S. P., Lahtinen, M., \& Sillanpää, M. (2010). Tansy fruit mediated greener synthesis of silver and gold nanoparticles. Process Biochemistry, 45(7), 10651071. https://doi.org/10.1016/j.procbio.2010.03.024

Feng, Y., Yu, Y., Wang, Y., \& Lin, X. (2007). Biosorption and bioreduction of trivalent aurum by photosynthetic bacteria Rhodobacter capsulatus. Current Microbiology, 55(5), 402-408. https://doi.org/10.1007/s00284-007-9007-6

Francis, G., Thombre, R., Parekh, F., \& Lekshminarayan, P. (2014). Bioinspired synthesis of gold nanoparticles using Ficus benghalensis (Indian Banyan) leaf extract. Chemical Science Transactions, 3(1), 470-474. https://doi.org/10.7598/cst2014.676

Gupta, P., Balaji, R., Parani, M., Chandra, T. S., Shukla, P., Kumar, A., \& Bandopadhyay, R. (2015). Phylogenetic analysis and biological characteristic tests of marine bacteria isolated from Southern Ocean (Indian sector) water. Acta Oceanologica Sinica, 34(8), 73-82. https://doi.org/10.1007/s13131-015-0709-5 Gupta, R., Mukherjee, K., \& Singh, S. (2014). In Silico characterization of nitrate reductase involved in gold nanoparticles synthesis in Pseudomonas denitrificans. International Journal of pharma and bio sciences, 5 (3), 376 - 388.

Haiss, W., Thanh, N. T., Aveyard, J., \& Fernig, D. G. (2007). Determination of size and concentration of gold nanoparticles from UV-Vis spectra. Analytical chemistry, 79(11), 4215-4221. https://doi.org/10.1021/ac0702084

Halder, A., Das, S., Bera, T., \& Mukherjee, A. (2017). Rapid synthesis for monodispersed gold nanoparticles in kaempferol and anti-leishmanial efficacy against wild and drug resistant strains. RSC Advances, 7(23), 14159-14167. https://doi.org/10.1039/c6ra28632a

Kathiresan, K., Manivannan, S., Nabeel, M. A., \& Dhivya, B. (2009). Studies on silver nanoparticles synthesized by a marine fungus, Penicillium fellutanum isolated from coastal mangrove sediment. Colloids and surfaces B: Biointerfaces, 71(1), 133-137. https://doi.org/10.1016/j.colsurfb.2009.01.016

Khalil, M. M., Ismail, E. H., \& El-Magdoub, F. (2012). Biosynthesis of $\mathrm{Au}$ nanoparticles using olive leaf extract: 1st nano updates. Arabian Journal of Chemistry, 5(4), 431-437. https://doi.org/10.1016/j.arabjc.2010.11.011

Kumari, M., Mishra, A., Pandey, S., Singh, S. P., Chaudhry, V., Mudiam, M. K. R., \& Nautiyal, C. S. (2016). Physico-chemical condition optimization during biosynthesis lead to development of improved and catalytically efficient gold nano particles. Scientific reports, 6. https://doi.org/10.1038/srep27575

Li, G., He, D., Qian, Y., Guan, B., Gao, S., Cui, Y., ... \& Wang, L. (2011) Fungus-mediated green synthesis of silver nanoparticles using Aspergillus terreus. International journal of molecular sciences, 13(1), 466-476 https://doi.org/10.3390/ijms13010466

Li, X., Xu, H., Chen, Z. S., \& Chen, G. (2011). Biosynthesis of nanoparticles by microorganisms and their applications. Journal of Nanomaterials, 2011. http://dx.doi.org/10.1155/2011/270974

Malarkodi, C., Rajeshkumar, S., Vanaja, M., Paulkumar, K., Gnanajobitha, G., \& Annadurai, G. (2013). Eco-friendly synthesis and characterization of gold nanoparticles using Klebsiella pneumoniae. Journal of Nanostructure in Chemistry, 3(1), 30. https://doi.org/10.1186/2193-8865-3-30

Malhotra, A., Dolma, K., Kaur, N., Rathore, Y. S., Mayilraj, S., \& Choudhury, A. R. (2013). Biosynthesis of gold and silver nanoparticles using a novel marine strain of Stenotrophomonas. Bioresource technology, 142, 727-731. https://doi.org/10.1016/j.biortech.2013.05.109

Mapala, K., \& Pattabi, M. (2017). Mimosa pudica Flower Extract Mediated Green Synthesis of Gold Nanoparticles. NanoWorld J, 3(2), 44-50. https://doi.org/10.17756/nwj.2017-045

Mukherjee, P., Roy, M., Mandal, B. P., Choudhury, S., Tewari, R., Tyagi, A. K., $\&$ Kale, S. P. (2012). Synthesis of uniform gold nanoparticles using nonpathogenic bio-control agent: Evolution of morphology from nano-spheres to 
triangular nanoprisms. Journal of colloid and interface science, 367(1), 148-152. https://doi.org/10.1016/j.jcis.2011.08.085

Nangia, Y., Wangoo, N., Goyal, N., Shekhawat, G., \& Suri, C. R. (2009). A novel bacterial isolate Stenotrophomonas maltophilia as living factory for synthesis of gold nanoparticles. Microbial Cell Factories, 8(1), 39. https://doi.org/10.1186/1475-2859-8-39

Pulit, J., \& Banach, M. (2013). Environment friendly method for obtaining gold nanoparticles based on plant extract. Digest J Nanomater Biostruct, 8(3), 1295 300 .

Rajathi, F. A. A., Parthiban, C., Kumar, V. G., \& Anantharaman, P. (2012). Biosynthesis of antibacterial gold nanoparticles using brown alga Stoechospermum marginatum (kützing). Spectrochimica Acta Part A: Molecular and Biomolecular Spectroscopy, 99, 166-173. https://doi.org/10.1016/j.saa.2012.08.081

Seshadri, S., Prakash, A., \& Kowshik, M. (2012). Biosynthesis of silver nanoparticles by marine bacterium, Idiomarina sp. PR58-8. Bulletin of Materials Science, 35(7), 1201-1205. https://doi.org/10.1007/s12034-012-0417-0

Sharma, N., Pinnaka, A. K., Raje, M., Ashish, F. N. U., Bhattacharyya, M. S., \& Choudhury, A. R. (2012). Exploitation of marine bacteria for production of gold nanoparticles. Microbial cell factories, 11(1), 86. https://doi.org/10.1186/14752859-11-86

Singaravelu, G., Arockiamary, J. S., Kumar, V. G., \& Govindaraju, K. (2007). A novel extracellular synthesis of monodisperse gold nanoparticles using marine alga, Sargassum wightii Greville. Colloids and surfaces B: Biointerfaces, 57(1), 97-101. https://doi.org/10.1016/j.colsurfb.2007.01.010

Singh, M., Kalaivani, R., Manikandan, S., Sangeetha, N., \& Kumaraguru, A. K. (2013). Facile green synthesis of variable metallic gold nanoparticle using Padina gymnospora, a brown marine macroalga. Applied Nanoscience, 3(2), 145-151. https://doi.org/10.1007/s13204-012-0115-7

Song, J. Y., Jang, H. K., \& Kim, B. S. (2009). Biological synthesis of gold nanoparticles using Magnolia kobus and Diopyros kaki leaf extracts. Process Biochemistry, 44(10), 1133-1138. https://doi.org/10.1016/j.procbio.2009.06.005

Suresh, A. K., Pelletier, D. A., Wang, W., Broich, M. L., Moon, J. W., Gu, B., .. \& Doktycz, M. J. (2011). Biofabrication of discrete spherical gold nanoparticles using the metal-reducing bacterium Shewanella oneidensis. Acta biomaterialia, 7(5), 2148-2152. https://doi.org/10.1016/j.actbio.2011.01.023

Thirumurugan, A., Ramachandran, S., Tomy, N. A., Jiflin, G. J., \& Rajagomathi, G. (2012). Biological synthesis of gold nanoparticles by Bacillus subtilis and evaluation of increased antimicrobial activity against clinical isolates. Korean Journal of Chemical Engineering, 1-5. https://doi.org/10.1007/s11814-012-0055$\underline{7}$

Zhang, X., Yan, S., Tyagi, R. D., \& Surampalli, R. Y. (2011). Synthesis of nanoparticles by microorganisms and their application in enhancing microbiological reaction rates. Chemosphere, 82(4), 489-494. https://doi.org/10.1016/i.chemosphere.2010.10.023 